Revista Brasileira de História \& Ciências Sociais - RBHCS

Vol. 13 No 25, Edição Especial de 2021

\title{
Menoridade e ameaça na bélle époque manaura, 1906 a 1917
}

\section{Minors and menaces in the Bélle Époque manaura, 1906 to 1917}

\section{Paulo Marreiro dos Santos Júnior*}

Resumo: O artigo pesquisou as estratégias de sobrevivência e o cotidiano de menores de idade da cidade de Manaus no período áureo da borracha, caracterizado como Bélle Époque, entre os anos de 1906 a 1917, período de transformação urbanística e arquitetônica, financiada pela riqueza do látex. A pesquisa evidencia um processo histórico de oposições e releituras ao fausto manauara, iluminando esquecidos da história da cidade. O objetivo do estudo é trazer à tona as experiências de 'menores' no cotidiano tenso da cidade que se via moderna, ocidentalizada, civilizada e europeizada. O estudo se justifica pela empreitada histórica de tirar das sombras vidas menos privilegiadas em meio à Bélle Époque manauara, a saber, os 'menores', passíveis de vigilância, estigmas, repressão e tolerância. Assim, esse trabalho propõe-se uma outra leitura do processo de formação da sociedade manauara - pelo viés desses 'menores'.

Palavras-chave: Menor idade. Criminalidade. Repressão.

Abstract: The article investigated the survival strategies and daily life of minors in the city of Manaus in the golden age of rubber, characterized as Bélle Époque, between the years 1906 to 1917, a period of urban and architectural transformation, financed by the wealth of latex. The research evidences a historical process of oppositions and reinterpretations to the manauara fausto, illuminating forgotten about the history of the city. The objective of the study is to bring to light the experiences of 'minors' in the tense daily life of the city that saw itself as modern, westernized, civilized and Europeanized. The study is justified by the historic endeavor to take less privileged lives out of the shadows in the middle of Bélle Époque manauara, namely the 'minors', subject to surveillance, stigmas, repression

* Doutor em história social pela PUC-SP. Professor no IFAM. 
Revista Brasileira de História \& Ciências Sociais - RBHCS

Vol. 13 No 25, Edição Especial de 2021

and tolerance. Thus, this work proposes another reading of the formation process of the society in Manaus - through the bias of these 'minors'.

Keywords: Underage. Crime. Repression

"Menor idade e ameaça na Bélle Époque manaura, 1906 a 1917" é um estudo que se contrapõe ao tradicionalismo historiográfico que cristalizou o mito do fausto da Manaus da época da Borracha, na virada dos séculos XIX e XX, período em que se consolidou a figura dos barões da goma elástica, da opulência arquitetônica, dos espetáculos de ópera no Teatro Amazonas, da pretensa europeização com a imigração estrangeira. Essa Manaus ficou conhecida no tempo como "Paris das Selvas" (DAOU. 1998, p. 173). A capital do Amazonas, retratada ainda hoje nos livros didáticos, documentários nostálgicos e viva na memória historicamente construída - dos citadinos locais é ausente de populares, sem contrastes, sem tensões, sem pobreza. A construção historiográfica tradicional consolidou a ideia de que a Manaus da Bélle Époque era isenta de segmentos sociais que ofuscassem seu brilho. Esse estudo busca contradizer tal vertente historiográfica, focando nas experiências vividas pelos 'menores' no cotidiano tenso da cidade, um dia-a-dia de segmentos sociais pouco privilegiados pela prosperidade da borracha, esquecidos pela história divulgada ao grande público. Os ditos 'menores', trânsfugas sociais para a Bélle Époque manauara, eram passíveis de vigilância, estigmatização, rótulo, repressão e tolerância.

Para essa perspectiva de análise, da História Social, lançou-se mão de fontes e metodologia que até à época deste estudo, e lá se vão quase vinte anos, eram desconsideradas ou muito incipientes na historiografia amazonense. A partir do olhar sobre o 'menor' o período da borracha é revisado por um olhar a "contrapelo" (BEMVINDO, 2016). Através das fontes históricas, a saber: colunas de jornais, códigos de postura, mensagens de autoridades, as ocorrências policiais e fotografias detonam que a "Paris dos Trópicos" foi remodelada para uma elite. Quanto às camadas mais pobres da população teriam que ser reconfiguradas, para estarem em consonância com as intenções europeizadoras das autoridades locais.

As fontes mais utilizadas para essa pesquisa foram as colunas do Jornal do Comércio do Amazonas. Este periódico foi inovador no contexto da imprensa local, 
Revista Brasileira de História \& Ciências Sociais - RBHCS

Vol. 13 No 25, Edição Especial de 2021

com o registro das "ocorrências policiais" que, em geral, denunciavam o movimento diário das delegacias de polícia da cidade. O modelo de escrita da época foi mantido, mantendo a originalidade dos fragmentos das fontes primárias.

Assim, o estudo sobre os 'menores' foi fundamentado documentalmente, na sua maioria, nas ocorrências policiais entre os anos 1906 a 1917, períodos que demarcaram extremos: do auge da economia gomífera (goma elástica) ao início da derrocada da borracha para Manaus.

Os registros de polícia já não existem nos arquivos de Manaus para o período da Belle Époque. Essa ausência de fonte policial oportunizou estudar as crônicas policiais do Jornal do Comércio para se compreender a dita criminalidade enquanto fenômeno social, uma vez que essas eram produtos dos registros policiais.

Nas crônicas policiais, constaram os registros de segmentos sociais que foram ordenados, classificados, hierarquizados, controlados. Um desses segmentos que compunham as notas jornalísticas das crônicas policiais do Jornal do Comércio foi a dos 'menores de idade'.

Os menores relatados nas crônicas foram os detidos pela polícia por crimes e/ou contravenções de época, como: vadiagem, furtos, desordem, destruição do patrimônio público, entre outros casos. Nesses casos, o percentual de menores passivos da intervenção policial foi muito pequeno. Os maiores percentuais envolviam menores que fugiam de seus tutores, casos que produziram inúmeras denúncias destes sobre seus tutelados fujões, provocando assim perseguições policiais aos fugitivos.

Mas, antes de esmiuçar o cotidiano desses 'menores' na Bélle Époque manauara, é necessário contextualizar o período, considerando que entre os séculos XIX e XX no Brasil houve o interesse de diversas instituições em compreender uma questão que já vinha se pronunciando enquanto representação de um problema social: o aumento da massa heterogênea de crianças pobres nas cidades. Esses segmentos sociais tinham condutas e ações que os tornavam passivos de enquadramentos das autoridades, classificações pelos estudiosos dos fenômenos sociais e rótulos da população local. A sociedade hegemônica da época, 
Revista Brasileira de História \& Ciências Sociais - RBHCS Vol. 13 No 25, Edição Especial de 2021

passou a projetar sobre o 'menor' o referencial de um estado atípico de infância, consequência de uma deterioração enquanto família.

Conforme visualizado na Figura I e II, “A Providencia Empresa Funerária” e "Tabacaria Indiana”, há a presença de menores nas fotografias, ao que parece, empregados das empresas. Os trajes formais, camisa manga longa, gravata, calça e sapato, típico das casas comerciais de Manaus, delata suspeita de relação trabalhista ou de possível tutela.

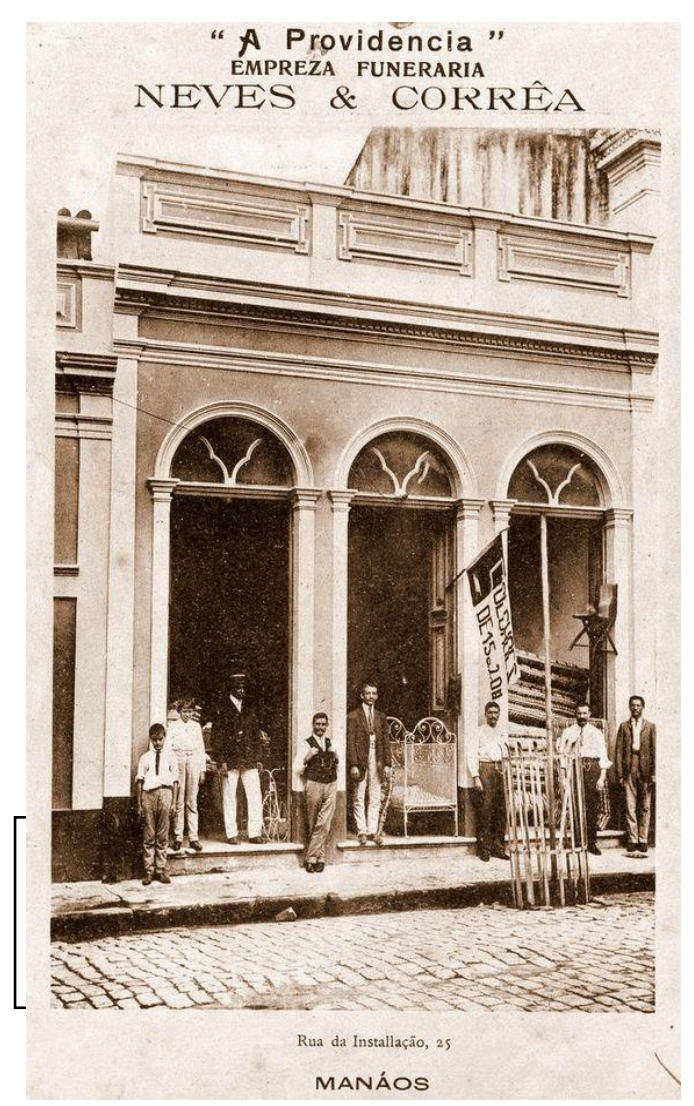

FIGURA I - A Providencia Empresa Funerária

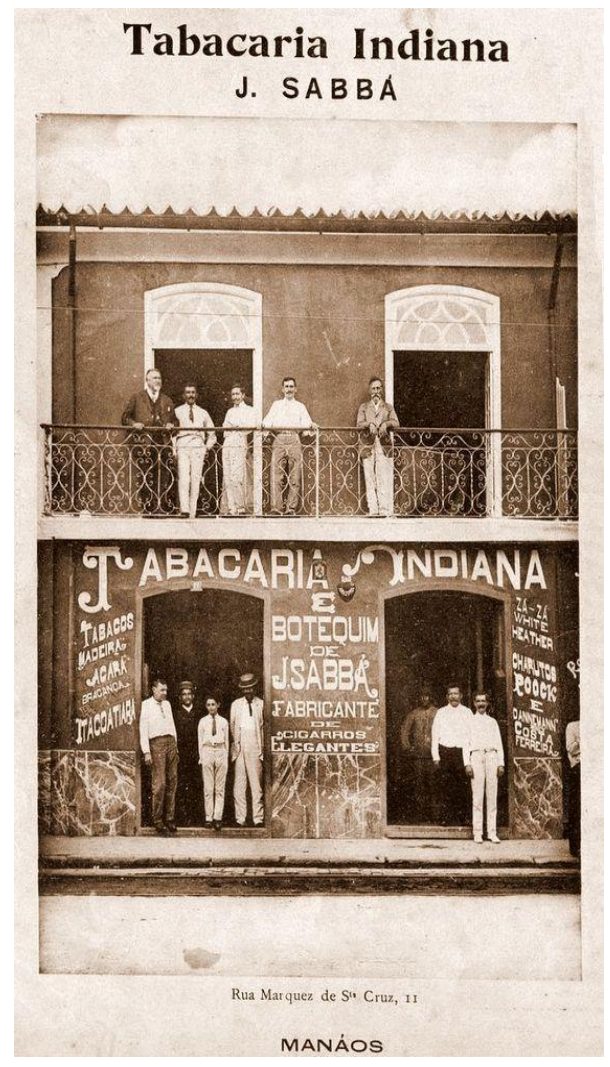

FIGURA II - Tabacaria Indiana

Fonte: Indicador Illustrado do Estado do Amazonas de 1910.

https://br.pinterest.com/pin/638244578415 495407/183887/ 
Revista Brasileira de História \& Ciências Sociais - RBHCS

Vol. 13 No 25, Edição Especial de 2021

Segundo Ivana Otto Rezende (2013), na consolidação da Primeira República no Brasil, as autoridades judiciárias buscaram ser as protagonistas da compreensão do problema e da formulação de soluções a respeito do 'menor'. Defendeu-se a criação de todo um arcabouço legal para os menores, que - em tese - deveriam ser tutelados pelo Estado. Os juristas da Primeira República brasileira baseavam-se em congressos internacionais que discutiam o aumento da "criminalidade infantil e juvenil". Passara a ser consenso nesses congressos a necessidade de uma "nova Justiça", na qual a educação para o trabalho deveria prevalecer em lugar da punição (REZENDE, 2013, p. 1).

Sobre a sociedade do período, nacional e local, formou-se um conjunto de implementações legais que justificavam intervenções no cotidiano vivido pelos menores, ações governamentais que seguiram na linha do higienismo, do domínio e transformação das áreas urbanas, da coerção da criminalidade, da imposição de ideais de trabalho, da inserção de novos hábitos e costumes e da criminalização de práticas sociais que foram consideradas afrontosas aos ditames da Primeira República no Brasil. A partir de 1906, diversos projetos de lei foram debatidos, visando regulamentar a pretensa proteção e a assistência à infância (REZENDE, 2013, p.1). Os menores eram somente um dos focos, mas que produziram inquietações tais a ponto de se elaborar toda uma legislação específica, objetivando formas mais incisivas de intervenção sobre suas vidas.

As políticas criadas pelo novo estado republicano brasileiro, destinadas a enquadrar a infância no modelo de nação pretendida, contribuiu para a construção do conceito social sobre o 'menor'. Na virada dos séculos XIX e XX, a preocupação maior era não permitir que tal segmento social se constituísse em obstáculo aos ideais de civilidade, modernidade, ordem e progresso que se pretendia com a Primeira República. Esta exigia, para além de um novo sistema econômico e político, a imperativa implantação de novos valores sociais, como trabalho e família, o que iria resultar em uma nova percepção sobre a criança, especialmente as das camadas menos abastadas, ou seja, dependendo da categoria social, das práticas cotidianas e da relação jurídica e todo o novo ideário estatal republicano, sobre essa criança poderia ser projetada a figura burlesca e nefasta do 'menor' (PESSOA, 2010). 
Revista Brasileira de História \& Ciências Sociais - RBHCS

Vol. 13 No 25, Edição Especial de 2021

Assim, para o senso de autoridades, imprensa e população hegemônica a criança passa a ser distinguida do 'menor'. Este "estava em vias de se transformar em um delinquente social e, portanto, um problema para o país. A criança, não se constituía problema, pois seria filha da elite, educada por um viés associado a relações clientalares” (REZENDE, 2013, p. 2).

Essa mentalidade hegemônica sobre o 'menor' passa a ser mais alimentada e retroalimentada no cotidiano tenso entre a infância infausta e as instituições estatais, a polícia e a justiça. Estas descritas nos trâmites processuais, essas relatadas pela imprensa mediante as crônicas policiais e aquelas registradas nos documentos oficiais e normatizadores dos órgãos de estado, como os educandários, códigos de postura e criminais.

No que tange à polícia, a partir das ações policiais sobre os 'menores', na sua ação repressora e controladora, ia-se qualificando e requalificando suas representações para o senso social, mediante rótulos e todo um jargão descrito nas ocorrências policiais. Portanto, "a polícia operacionalizava os significados que compunham o universo simbólico do menor" (REZENDE, 2013, p. 3). Assim sendo, esse simbolismo, através das ocorrências policiais do Jornal do Comércio e também de outros órgãos de imprensa, era o que nutria e renutria o imaginário coletivo e hegemônico sobre a figura do 'menor' na cidade de Manaus.

Do ponto de vista jurídico, a construção simbólica do 'menor' pode ser apreendida nas transcrições dos processos de "tutela" do Juizado de Órfãos (PESSOA, 2010; REZENDE, 2013).

O que coube aos governantes locais, alinhados aos novos padrões sociais da Primeira República, a conduta do 'menor' foi estipulada nos documentos oficiais, como: o Código Penal Republicano do Brasil de 1890, nos fundamentos dos Institutos Affonso Penna e Benjamin Constant, educandários responsáveis pela reconfiguração moral e social desse 'menor', adestrando-o para o trabalho, e numa diversidade de mensagens oficiais de governo, (PESSOA, 2010; REZENDE, 2013).

Quanto às crônicas policiais, que é a principal fonte primária deste estudo, foram registrados os aumentos gradativos de ocorrências envolvendo menores como vítimas e/ou algozes. Vítimas quando eram passíveis de repreensões de seus responsáveis, esses fundamentados em concepções de ordem e posturas 
Revista Brasileira de História \& Ciências Sociais - RBHCS

Vol. 13 No 25, Edição Especial de 2021

comportamentais consolidadas, às vezes para tanto beirando espancamentos e castigos. Algozes quando os noticiados não eram seus responsáveis, mas os ditos menores quando produziam ações que estavam em desacordo com a norma estabelecida: "meninos" que andavam nos estribos dos bondes, atiravam pedras nas fruteiras das praças da cidade, pulavam os muros das casas motivados por suas brincadeiras, reuniam-se "suspeitamente" em espaços da cidade, furtavam seus patrões, tutores e transeuntes.

A tabela I reproduz o reflexo de ocorrências que envolvem infrações de ou contra menores nos seus múltiplos casos, produzindo assim prisões e/ou queixas presentes nas crônicas policiais.

TABELA I

No de ocorrências envolvendo menores

\begin{tabular}{|c|c|c|c|c|c||}
\hline 1906 & 1908 & 1909 & 1910 & $1916 /$ & TOTAL \\
& & & & 7 & \\
\hline 5 & 15 & 25 & 54 & 49 & 148 \\
\hline
\end{tabular}

Fonte: Jornal do Comércio: 1906, 1908 - 1910, 1916, 1917.

Do quantitativo listado na tabela I, foram separados os percentuais das ocorrências envolvendo menores em três macro-grupos, que produziram os seguintes resultados: violência cometida aos menores: 31,01\%; fuga de menores de seus responsáveis/tutores: 62,02\%; delinqüência envolvendo menores (furtos e outros): $6,32 \%$.

Em todos os casos estudados os personagens centrais eram genericamente chamados de "menores". Mas lendo nas entrelinhas do contexto da cidade, percebeu-se que as homogeneizações produziriam equívocos. Por isso, em um contexto de tradições e comportamentos bem definidos, tornou-se necessário perceber as diferenças. Logo, "menor" também não representava estar preso a limites etários.

De Janauacá, onde reside, Manaoel Raymundo de Menezes, veiu queixarse á policia contra Manoel Francisco da Matta, que lhe raptara a sua filha Claudina Maria. Pela $1^{\mathrm{o}}$ delegacia foram tomadas as providencias no sentido de ser preso o raptor da menor, que conta 27 anos de edade (Jornal do Comércio. Factos Policiaes: 14 de abril de 1910). 
Revista Brasileira de História \& Ciências Sociais - RBHCS

Vol. 13 No 25, Edição Especial de 2021

Pelo que constava, Claudina Maria, mesmo estando com 27 anos foi considerada pelo pai, pela polícia e pela redação das crônicas policiais totalmente incapaz de autogestão, tendo a agravante de ser considerada implicitamente não uma vítima de rapto, mas uma fugitiva, que partiu com o seu pretendente. Considerada menor, Claudina Maria, conjuntamente com seu dito raptor, passa a ser uma personagem considerada fora da norma, e por isso, passível de perseguição policial para que seja entregue ao seu legítimo responsável, conforme o senso social e moral da época: seu pai. A discussão sobre a ocorrência em questão é efetivamente sobre a relação de menoridade. Mas compreende-se que para além dessa questão, a ocorrência envolve relações de poder e gênero. Uma vez que há casos pitorescos semelhantes nos longínquos rincões de estados brasileiros do século, como o Janauacá (região do interior do estado do Amazonas), casos em que filhas solteiras eram aprisionadas por seus pais, procedimento visto como habitual em relação às filhas de família, (TRINDADE, 1996, p. 109-120).

Portanto, ser identificado enquanto um 'menor' era estar incapaz de se autogerir, não tendo sobre si a posse de seu destino e existência, sendo distinguido de demais categorias etárias pela sua dimensão relacional e de contraste com a polícia que lhe construía uma identidade, para além de seu status jurídico (Código Civil de 1916).

Era dessa forma, para além do status jurídico da menoridade, associando componentes culturais, que se legitimavam as intervenções policiais sobre os menores, produzindo sobre os menores maiores subordinações na hierarquia social.

$\mathrm{Na}$ Manaus da Borracha, no que tange ao índice de $6.32 \%$ de ocorrências apontando menores como criminosos, a intervenção policial atribuiu a determinadas práticas a idéia de desvio. Brincadeiras de "crianças" passavam a desordem de “menores”, e por isso, submetidas à intervenção policial, como ordena o Chefe de Segurança Pública.

Designar uma auctoridade para a avenida Eduardo Ribeiro, afim de fazer cessar a algazarra que costumam fazer uns menores italianos, bem como na rua Municipal, entre a referida avenida e a rua da Installação; designar um agente para impedir que outros menores na avenida Silvério Nery, tomem os carros da viação e d'elles 
Revista Brasileira de História \& Ciências Sociais - RBHCS

Vol. 13 No 25, Edição Especial de 2021

saltem estando os mesmos em movimento (Diário Oficial do Estado do AM. Chefatura de Segurança Pública, 5 de fevereiro de 1905, ${ }^{\circ} 3234$ ).

Como as demais categorias sociais, os menores da Manaus da Borracha deveriam ser educados pelas autoridades. Não convinha estarem ocupados com práticas pouco edificantes, ou pelo menos, não deveriam estar 'desocupados', como foi apontado por moradores indispostos com certos menores.

\begin{abstract}
Alguns moradores da rua Lima Bacury, pedem-nos que chamemos a attenção de quem competir, para uns menores desoccupados que têm por costume empinar papagaios nas immediações d'aquela rua.

Costumam esses meninos subirem aos muros de vários quintaes, notadamente nos de ns. 74 a 78 da rua Izabel, de onde tudo devassam, observando o que fazem as famílias no interior de suas casas, que por esse motivo se vêem na impossibilidade de fazer uso dos seus banheiros (Jornal do Comércio. Queixas do Povo: 21 de abril de 1909).
\end{abstract}

A condição de "desocupados" e/ou desordeiros era algo que preocupava as autoridades. Na Manaus da Borracha, no auge do seu processo de transformação urbanística, arquitetônica, era necessário que sua população também fosse transformada, em conformidade com os ideais da Primeira República. Logo, era inaceitável citadinos que perambulavam sem trabalho e/ou moradia fixa. A tríade trabalho, moral e família deveriam andar sempre juntas numa Manaus ordeira, progressista e civilizada. Num contexto em que o trabalho infantil além de legitimado era valorizado social e moralmente, meninos e meninas das camadas populares não deveriam ficar imunes a tais perfis. Crianças pobres vagueando pela cidade, poderiam ser alvos da contenção policial, sendo reconhecidas pelos organismos de Estado como 'menores' ociosos, “um mal a ser combatido, pois ele era a causa do atraso, era a negação do progresso. Era necessário exterminar a vadiagem, para se chegar a tão almejada civilização" (CHALHOUB apud PESSOA, 2010, p. 49).

Sendo assim, menores deveriam ser um dos alvos permanentes de vigilância e repressão policial, ou até mesmo reclusão. Conforme Alba Barbosa Pessoa (2010) no primeiro Código Penal Republicano do Brasil, de 1890, ficava constituído que "Não são criminosos os menores de nove annos completos" nem os "maiores de 9 anos e menores de 14, que obrarem sem discernimento" (SANTOS apud PESSOA, 2010, p. 50). Aos menores entre os nove e quatorze anos de idade que cometessem 
Revista Brasileira de História \& Ciências Sociais - RBHCS

Vol. 13 No 25, Edição Especial de 2021

crimes em plena sã consciência e/ou reincidentes, seriam conduzidos a estabelecimentos disciplinares industriais, até 17 anos de idade no máximo. Além da incômoda presença do menor ser retirado das vistas da urbe, ele seria moralmente regenerado através do trabalho.

Com o aumento das migrações de populares do interior para a capital, como também de nordestinos fugidos da seca e estrangeiros pobres como barbadianos, peruanos, bolivianos e outros imigrantes relatados pela imprensa e com agravamento da crise da borracha, uma massa de desvalidos trazia sérios riscos à manutenção da ordem pública.

De 1906 ao primeiro bimestre de 1909, não se têm relatos no Jornal do Comércio de que menores provocassem maiores danos. Até então, as intervenções policiais tinham o intuito de restringir comportamentos considerados desqualificados, como as algazarras, pular de estribos de bondes em movimento ou sobre os muros das casas, atirar pedras em mangueiras das praças, entre outros casos. Mas, a partir de 1909, tem-se notícia de grupos de menores infratores que furtavam transeuntes nas ruas da cidade.

$\mathrm{Na} 1^{\circ}$ delegacia queixou-se Sotero Antonio Mendes Cabral, que 4 menores lhe haviam furtado uma bolsa com dinheiro. Sendo preso dois dos precoces gatunos, foi encontrado em poder dos mesmos ainda a quantia de 28.00o réis (Jornal do Comércio. Factos Policiaes: 6 de março de 1909).

No mesmo dia, outro caso envolvendo menores infratores foi estampado nas páginas policiais, não havendo exatidão se fora uma resultante do caso anterior.

Foi preso pelo agente Coriolano, o menor Manoel Antonio da Silva por gatunagem e pelo mesmo motivo foram, ás 4 horas da tarde presos os menores Francisco Pontes de Miranda e Américo Gil, encontrando-se em poder deste ultimo a quantia de 6.000 réis (Jornal do Comércio. Factos Policiaes: 6 de março de 1909).

Conforme as crônicas policiais, esses foram os únicos casos - entre 1906 e 1917 - noticiados que indicaram grupos organizados de menores, como também foram os únicos casos que o redator adjetivou menores de "gatunos".

Pela ausência de outras fontes primárias, não ficou muito claro se os casos noticiados de furto por grupos de menores eram recorrentes na cidade. O que ficou evidente foi a intencionalidade de impedir o aumento de sua incidência, como de outras práticas ditas nefastas por tais menores, através de um modelo jurídico que, 
Revista Brasileira de História \& Ciências Sociais - RBHCS

Vol. 13 No 25, Edição Especial de 2021

em tese, satisfaria as necessidades de mão-de-obra, como corrigiria as deficiências desses menores desvalidos e/ou abandonadas: a tutoria.

De acordo com o trabalho de Alba Barbosa Pessoa, "Infância e Trabalho Dimensões do Trabalho Infantil na Cidade de Manaus (1890-1920) ", no que se referente ao Juízo dos Órfãos da Cidade de Manaus, a polícia auxilia Juízo nas questões referentes às crianças. A população e todos os órgãos públicos administrativos recorriam ao Juízo quando se tratava de "tutela", também denominada "tutoria".

No transcorrer de Império para Primeira República, a tutela passa a atender aos filhos das famílias pobres. Pessoa (2010) conclui que:

(...) poderiam ser tuteladas as crianças órfãs de pai e mãe, as desamparadas e as que os pais que, por não terem recursos para criá-las, assim solicitassem. Ao juizado dos Órfãos caberia intermediar essa relação. Ao assinar o termo de Tutela, o tutor se comprometia em alimentar, vestir educar e ensinar um ofício à criança tutelada. Entretanto, no período republicano ele também vai se estender aos filhos cujos pais demonstrassem posturas "inadequadas" para o convívio de uma criança. A partir de então bastava que um "homem de respeito" solicitasse a tutela de um menor alegando que os pais não possuíam condições morais ou financeiras de criá-lo, para que o juiz desse a guarda a esse cidadão mesmo que os pais a isso se opusessem. (PESSOA, 2010, p.66).

Assim sendo, as frequentes solicitações de pedidos de tutelas tinham como base a suposta falta de condições financeiras de pais e/ou mãe de criarem seus filhos e de dar-lhes boa educação. Com o agravante de que a carestia social não era a única motivação para a tutela, a chamada "moralidade duvidosa" ou uma "vida airada" (Jornal do Comércio do Amazonas) dos pais era o suficiente para o Juízo de Órfãos retirar os menores do convívio familiar concedê-los à tutela, em resposta a uma solicitação de pedido de tutela sobre um menor, com a finalidade de dar ao menor educação e bom exemplo. Tal ação jurídica era considerada um ato de caridade. Mediante "Autos de Petição dirigida ao Juízo dos Órfãos em Manaus", Pessoa (2010) conclui que "a falta de condição moral e financeira de criar os filhos foi argumento frequente nos pedidos de tutela de menores", (PESSOA, 2010, p.59,60).

Todo um aparato legal concatenava-se com a tutela. Conforme o artigo 399 do Código Penal de 1890, menores desocupados ou considerados "vadios" 


\section{Revista Brasileira de História \& Ciências Sociais - RBHCS}

Vol. 13 No 25, Edição Especial de 2021

deveriam ser enviados para estabelecimentos industriais, nos quais trabalhariam até os 21 anos, caso fossem maiores de 14 anos.

DOS VADIOS E CAPOEIRAS

Art. 399. Deixar de exercitar profissão, officio, ou qualquer mister em que ganhe a vida, não possuindo meios de subsistencia e domicilio certo em que habite; prover a subsistencia por meio de occupação prohibida por lei, ou manifestamente offensiva da moral e dos bons costumes:

Pena - de prisão cellular por quinze a trinta dias.

$\S 1^{\mathrm{o}}$ Pela mesma sentença que condemnar o infractor como vadio, ou vagabundo, será elle obrigado a assignar termo de tomar occupação dentro de 15 dias, contados do cumprimento da pena.

$\S 2^{\circ}$ Os maiores de 14 annos serão recolhidos a estabelecimentos disciplinares industriaes, onde poderão ser conservados até á idade de 21 annos.

Art. 40o. Si o termo for quebrado, o que importará reincidencia, o infractor será recolhido, por um a tres annos, a colonias penaes que se fundarem em ilhas maritimas, ou nas fronteiras do territorio nacional, podendo para esse fim ser aproveitados os presidios militares existentes. (Decreto $\mathrm{n}^{\circ} 847$, de 11 de outubro de 1890).

Como na Manaus da Borracha, as manufaturas eram poucas e as indústrias incipientes, os menores foram estabelecidos também às casas comerciais, como em residências de famílias tidas "de bem" ou de "homens de respeito". A responsabilidade legal do tutor era "alimentar, vestir educar e ensinar um ofício à criança tutelada”. Contudo, muitos dos menores tutelados eram destinados aos serviços domésticos e trabalhos que em nada lembravam o ensino de um ofício.

O Código Penal de 1890 refletia um problema social que vinha sendo percebido por autoridades em Manaus desde os primeiros anos do século XX.

Outro assunto que merece nosso acurado estudo e demanda solução prompta é a vadiagem de menores. A polícia sem meios de leva-los ao trabalho limita-se a envia-los ao juízo de órfãos que fica na contingência de entrega-los sob tutela da qual sempre fogem para de novo tornar a mesma vida desregrada e ociosa. Deter as crianças sem ocupação no xadrez da polícia, em promiscuidade com criminosos antigos é acto que não deve ser aconselhado. $\mathrm{E}$ das dificuldades resultantes aparece como único meio de abreviar a situação. $O$ estabelecimento de uma escola correcional ou instituto que outro nome tenha mais preparado para formar o caráter e educar o espírito, é incontestavelmente o magno serviço prestado à infância desvalida, digna por certo da proteção dos altos poderes do estado. (Mensagem lida durante o congresso dos senhores representantes por ocasião da abertura $1^{\circ}$ seção ordinária da $5^{\circ}$ legislatura pelo governador do estado excelentíssimo senhor doutor Silvério José Nery em 10 de julho de 1904. Biblioteca da Associação Comercial do Amazonas).

O principal problema enfrentado pela polícia frente aos menores era o da vadiagem. Conforme a mensagem, mesmo a polícia prendendo os menores vadios e 
Revista Brasileira de História \& Ciências Sociais - RBHCS

Vol. 13 No 25, Edição Especial de 2021

o juiz de órfãos entregando-os a terceiros na condição de tutelados, os mesmos "fogem para de novo tornar a mesma vida desregrada e ociosa". Foi sobre essa relação tensa entre tutores e tutelados que $62.02 \%$ das crônicas policiais se fundamentaram. Desse percentual, 95\% dos casos registrados sobre fuga de menores envolviam tutelados, o restante envolvia fuga de pais ou parentes diretos.

Ás seis horas da tarde de hontem, compareceu á $2^{0}$ delegacia, Manoel Pacheco Barbosa e communicou á auctoridade de permanência que de sua casa á rua Quintino Bocayuva n. 74, desapparecera á 2 horas, uma sua tutellada, de 15 annos de edade, mulata, de nome Maria (Jornal do Comércio. Menor desapparecida: 12 de janeiro de 1909).

A denúncia produzida através das fugas de menores mostrava como o cotidiano de sua relação era tensa com seus tutores. Em algumas ocorrências policiais, o tutor, de vítima, passava a ser acusado de algoz, considerando denúncias ou suspeitas de maus tratos, o que provocava a fuga. Um ou outro caso, o que deveria ser registrado de forma mais incisiva era que as ocorrências policiais envolvendo fuga de menores, tutelados ou não, trouxeram à baila todo um cotidiano tenso envolvendo criminalidade, menoridade, controle e exploração.

No dia 8 do corrente, desappareceu da residência de Antonio Gonçalves Veloso á rua Henrique Martins 93, uma pequena de 12 annos de idade, sua tutellada. A policia teve conhecimento do facto (Jornal do Comércio. Factos Policiaes: 11 de abril de 1909).

Conforme a mensagem de governo, para as autoridades locais, os menores deveriam "formar o caráter e educar o espírito". O Código Civil de 1916 veio tratar com mais empenho a questão, havendo toda uma legitimação de resgate de menores de seus progenitores que não os disciplinassem a contento. A domesticação familiar não podia falhar no tocante aos padrões de comportamento idealizados. Foi associada à vadiagem a moralidade - ou a falta dessa - enquanto questão. Progenitores perderiam a guarda de seus filhos caso fossem considerados incapazes moralmente.

395. Perderá por ato judicial do pátrio poder o pai, ou mãe:

III - Que praticar atos contrários à moral e aos bons costumes (Código Civil. Lei $\mathrm{n}^{\circ} 3071 \mathrm{de} 1^{\circ}$ de janeiro de 1916. Livro I - Das Pessoas. Título I da Divisão das Pessoas. Capítulo VI - do Pátrio poder. Título V - das Relações de Parentesco. Seção IV - da Suspensão e Extinção do Pátrio Poder. Art..In: "Código Civil Atualizado", Coleção Lex, Edt. Aurora, $35^{\circ}$ edição. Biblioteca do Tribunal de Justiça. Manaus-Amazonas). 
Revista Brasileira de História \& Ciências Sociais - RBHCS

Vol. 13 No 25, Edição Especial de 2021

Na mentalidade hegemônica, senso dos governantes e legislações envoltas à Primeira República e à Bélle Époque manauara, o trabalho era o mecanismo mais eficiente para se evitar a vadiagem do menor, conforme evidencia as Figuras II e III.

Nessas figuras, é mostrado a aglomeração de diversos populares em alguma festividade na cidade de Manaus. A presença de uma pequena tropa de soldados ao fundo da imagem denuncia o grau de importância do evento. A fonte não indica detalhes. Porém, chama a atenção a quantidade e diversidade de 'meninos'. Um desses merece destaque: intitulado "Menino Doceiro" evidencia o trabalho infantil. Favorável pelos ditames de moral e bons costumes da época.

FIGURA II - Populares da cidade

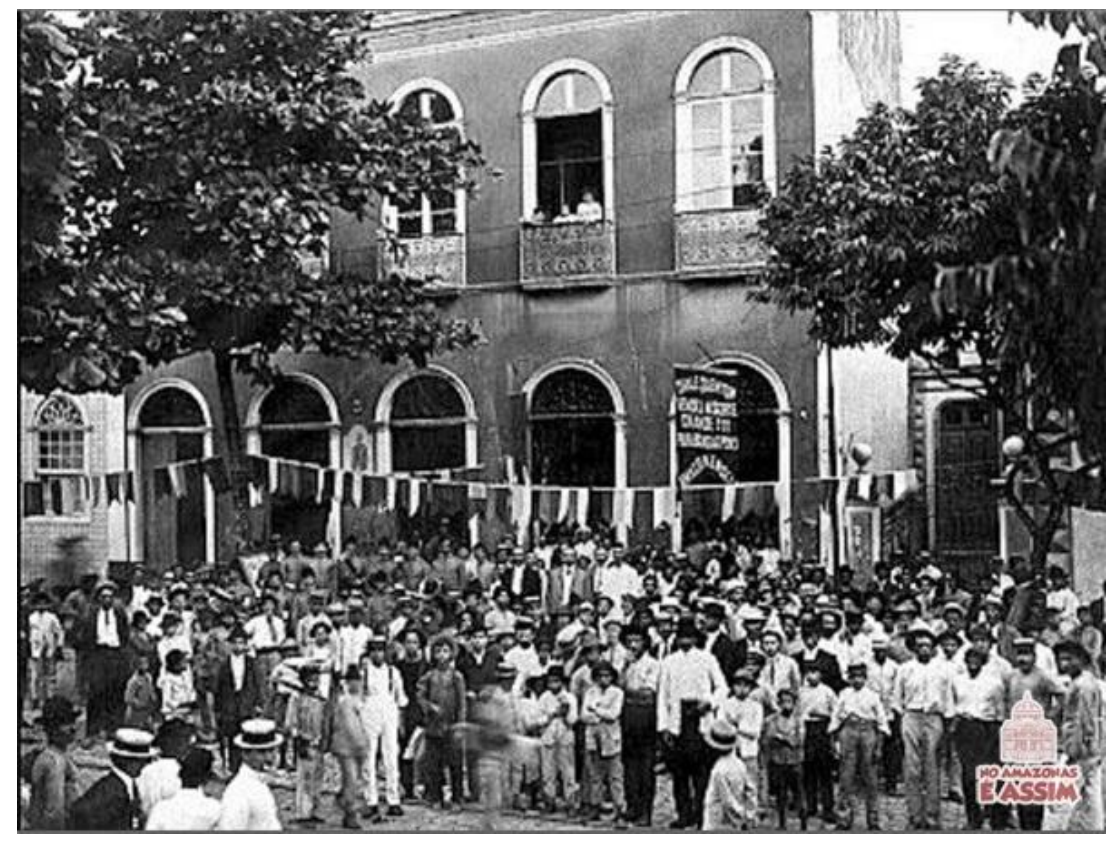

FIGURA III - Menino Doceiro

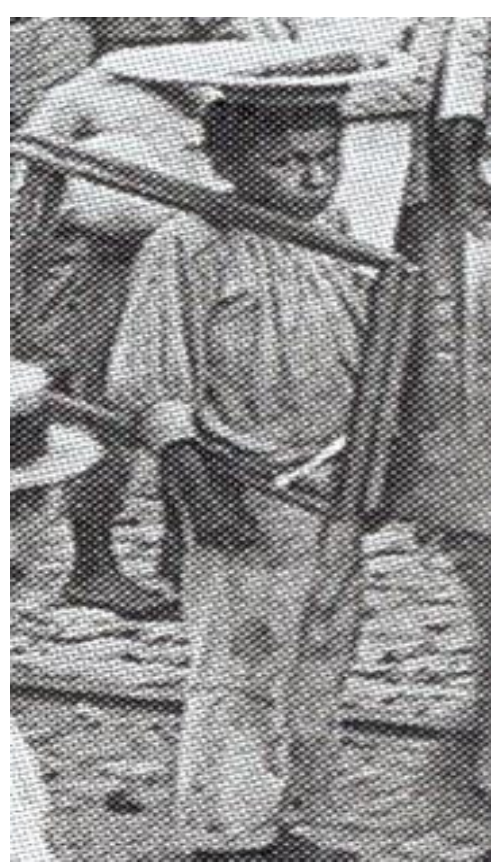

Figura II. Populares e diversos menores em Manaus. Figura III. Fragmento da foto anterior. "Menino Doceiro".

Fonte: https://marcuspessoa.com.br/conheca-o-lado-desumano-da-belle-epoque-que-voce-naoaprende-nos-livros-tradicionais/.1906(?)

O fato era que órfãos ou resgatados por mandado judicial seriam sujeitados à política de enquadramento social. De acordo com os objetivos das autoridades, essa política de enquadramento social sustentava-se no controle e repressão dos 


\section{Revista Brasileira de História \& Ciências Sociais - RBHCS}

menores ociosos que desrespeitavam a ordem estabelecida. Era imperativo que costumes tidos como "degenerados" fossem corrigidos desde a infância, pois assim se transformariam em futuros trabalhadores. Tornou-se fundamental que cenas de ociosidade, como as relatadas pela imprensa local, fossem transformadas.

Tratava-se de um número muito grande de meninos, que passavam o dia às sombras das árvores, conversando ou jogando bola, incomodando com sua ociosidade as autoridades. A imprensa promove uma campanha contra esse "mau costume" que está se desenvolvendo em Manaus, solicitando inclusive que a polícia tome providências, retirando-os da rua, encaminhando para estabelecimentos públicos onde, com disciplina e rigor, pudessem se regenerar da vadiagem. Manaus, cidade civilizada, não devia oferecer espetáculos desta natureza (DIAS, 1999, p. 148-149).

Nesse sentido, a polícia representou um componente importante na imposição de um novo cotidiano urbano, este centralizado no trabalho, como um modo de controle e transformação social. Era intuito das autoridades incutir nos menores a difusão do valor social do trabalho, para, além disso, a polícia tinha a função de vigiar e impor hábitos. 
Revista Brasileira de História \& Ciências Sociais - RBHCS

Vol. 13 No 25, Edição Especial de 2021

FIGURA IV - Menino Jornaleiro

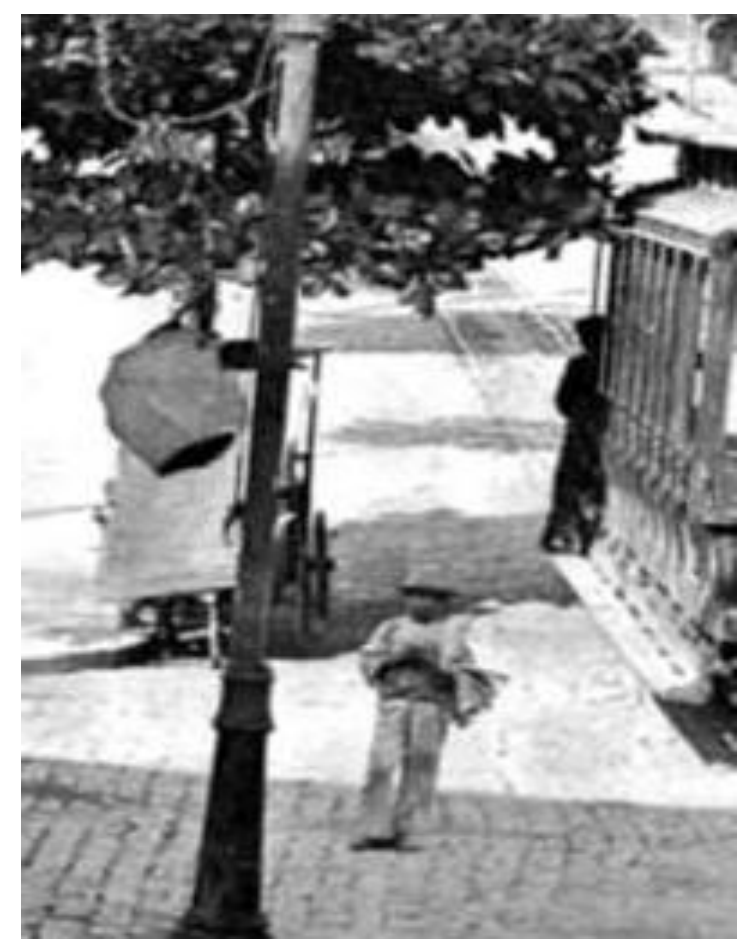

Fragmento de imagem de vídeo que retrata por meio de fotos a belle époque manauara. Fonte: https://www.youtube.com/watch?v=OkkJA6mx1ZU
FIGURA V - Menino Engraxate

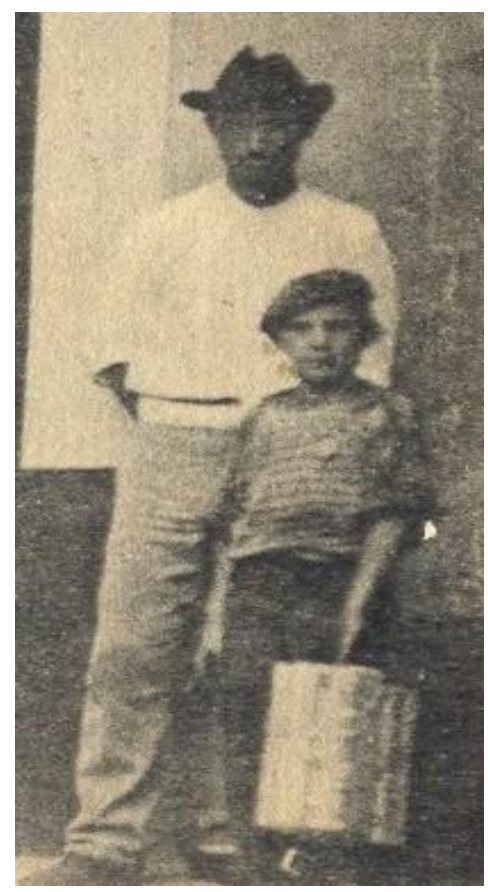

Fonte: acervo pessoal, Dr. Luiz Balkar. Manaus, início do século XX.

Como antes de 1917 não havia sido implementado algum tipo de orfanato, a polícia recolhia das ruas os menores vadios. Mesmo esses sendo entregues aos pais, não eram obrigados à prática do trabalho, possibilitando o retorno à vadiagem.

Através do Código Penal de 1890 e mediante o Código Civil de 1916, as autoridades públicas legitimaram o regime de tutoria, realizada por famílias que se dispunham como responsáveis dos órfãos ou menores vadios, muitas vezes resgatados de pais que perderam o pátrio poder, como já visto em parágrafos anterior.

Mas a disposição de famílias voluntárias à tutoria seria por aspiração filantrópica, ou visavam explorar esses menores?

Em um período que eram recorrentes os casos de exploração da mão-deobra, ser tutor de um menor representava possuir um trabalhador potencialmente dócil, domesticado e obediente, que possibilitaria bons lucros, já que a única 
Revista Brasileira de História \& Ciências Sociais - RBHCS

Vol. 13 No 25, Edição Especial de 2021

obrigatoriedade de um tutor, sendo na prática um patrão, era compensar o tutorado-empregado com alimentação, abrigo e ofício, aprendizado que em muitos casos não acontecia. Assim, o menor produziria muito e em troca receberia praticamente nada.

Nessa relação patronal entre tutor/tutelado, muitos eram os menores que furtavam seus tutores/patrões e fugiam em seguida. Com um caráter às vezes burlesco, o furto representava uma forma de compensação pelo tempo de expropriação, e a fuga, um retorno a suas práticas condenadas enquanto menor.

O sr. Conrado Tavares Filho, tendo sua esposa necessidade de certos objectos do mercado, para lá fez seguir o seu criado menor de nome Jorge José da Costa, moleque esperto e de olho vivo, para compral-os.

Escusado será dizer que, de um cabra experto, só se podia esperar o que fez o Jorge José: abalou elle com as compras e tudo.

Cansado de o esperar, sentado, o sr. Conrado, levantou-se e andou á pista do gajo, tudo de balde, já se vê: foi para a policia de um prompto e lá deixou a sua queixa (Jornal do Comércio. Coisas Policiais: "Passarinho bateu asas", 12 de junho de 1917).

Naqueles dias, os trabalhos prestados por um menor eram variados, desde serviços domésticos, como no caso de Jorge José da Costa, passando por trabalhos diversos em casas comerciais, como os de caixeiros, até o mais massacrante nos seringais. Para esses últimos que estavam na iminência de serem mandados ou vivenciaram a agonia da servidão nos seringais, fugir era uma forma de resistência à política rural de transferência forçada para o campo. Essa política de remoção era indicada para adultos "desocupados", mas como um dos objetivos era a obtenção de maiores lucros, resguardada pela política de controle social, o envio de menores aos seringais tornou-se uma das estratégias utilizadas por autoridades e particulares ambiciosos.

Na primeira delegacia encontra-se o menor Waldemar Pontes de Lima, de quatorze annos, filho de Fausta Maria da Cruz, vindo do Pará, no vapor nacional Recife, em companhia do turco Salis Salim, e encontrado no hotel Madeira, á praça dos Remedios.

Este menor ia sendo levado para o interior numa leva de seringueiros e por ser orphão de pae, constando ter fugido de casa, ficou á disposição do juiz de órfãos (Jornal do Comércio. Coisas Policiais: "Para o captiveiro", 17 de junho de 1917).

A combinação entre menoridade, miséria e exploração chegava a tanto que, em 1910, foi aberto um inquérito que buscava investigar a venda de menores do Ceará rumo a Manaus. 


\section{Revista Brasileira de História \& Ciências Sociais - RBHCS}

Vol. 13 No 25, Edição Especial de 2021

$\mathrm{O}$ subdelegado Braule Pinto, da $2^{\mathrm{O}}$ delegacia, abriu rigoroso inquérito sobre a venda de menores que se faz no Estado do Ceará, para o interior do Amazonas. Ultimamente, a bordo do vapor Esperança, chegou a esta capital no dia 5 de abril ultimo a menor Raymunda Rodrigues, de 15 anos de edade, que foi vendida por sua mãe Maria Alves de Lima a João Caetano, pela qantia de $20 \$$. O facto da venda passou-se na cidade de Aracaty, Estado do Ceará. A policia prosegue no inquérito. Jornal do comercio. Factos Policiaes: 3 de maio de 1910.

Mas, mesmo que a política de remoção ao campo fosse mais eficiente no que tange ao controle sobre os "sujeitos indesejáveis", era na cidade que estava o maior índice de submissão aos menores.

Sob o ponto de vista do Código Civil de 1916, na ausência de orfanatos apropriados, o tutor representava o agente da ordem mais próximo no cotidiano do menor, na casa ou estabelecimento do tutor se acreditava que o menor aprenderia os bons conceitos de ordem, disciplina, agregando valores morais por via do trabalho e aprendendo um ofício que lhe serviria para o futuro.

Art. 412. Os menores abandonados terão tutores nomeados pelo juiz, ou serão recolhidos a estabelecimentos públicos para este fim destinados. $\mathrm{Na}$ falta dêsses estabelecimentos, ficam sob a tutela das pessoas que, voluntariamente, se encarregarem da sua criação (Código Civil. Título VI - da Tutela, da Curatela e da Ausência. Capítulo I - da Tutela - Seção. I dos Tutores. Lei ${ }^{\circ} 3071$ de $1^{\circ}$ de janeiro de $1916,35^{\circ}$ edição. Biblioteca do Tribunal de Justiça. Manaus-Amazonas).

Mas para o menor, a tutela era um cárcere, e o tutor era uma espécie de agente prisional que, em muitos casos, submetia o menor a violências extremas e exploração.

Esse cotidiano visto como tensão revelou que as práticas da tutela não exerciam seu papel de forma tão digna quanto se esperava e anunciava, não englobando o que o sistema de tutela pretendia. Era da responsabilidade dos tutores "se encarregarem da sua criação". Conforme consta na Figura V, que trata da "Provisão de Tutela", em favor de Ismael Benigno da Costa, para fins da tutela de Francisco (Manaus, 4 de junho de 1909).

No que tange às meninas tuteladas, muitas foram defloradas por seus tutores/patrões, casos de significativa recorrência nas crônicas policiais.

Ao dr. Promotor publico do $1^{\mathrm{o}}$ districto judiciário foi hontem remettido, pelo escrivão Luiz Elysio, do $1^{0}$ districto policial, o inquérito ex-officio procedido com relação ao defloramento da menor Maria Luiza do Espírito-Santo, de que é accusado Romualdo Caetano Rodrigues, pratico 
Revista Brasileira de História \& Ciências Sociais - RBHCS

Vol. 13 No 25, Edição Especial de 2021

de bordo e patrão dessa menor (Jornal do Comércio. Chronica Policial: 15 de abril de 1908).

FIGURA V - Provisão de Tutela

\section{PROVISÃO DE TUTELA}

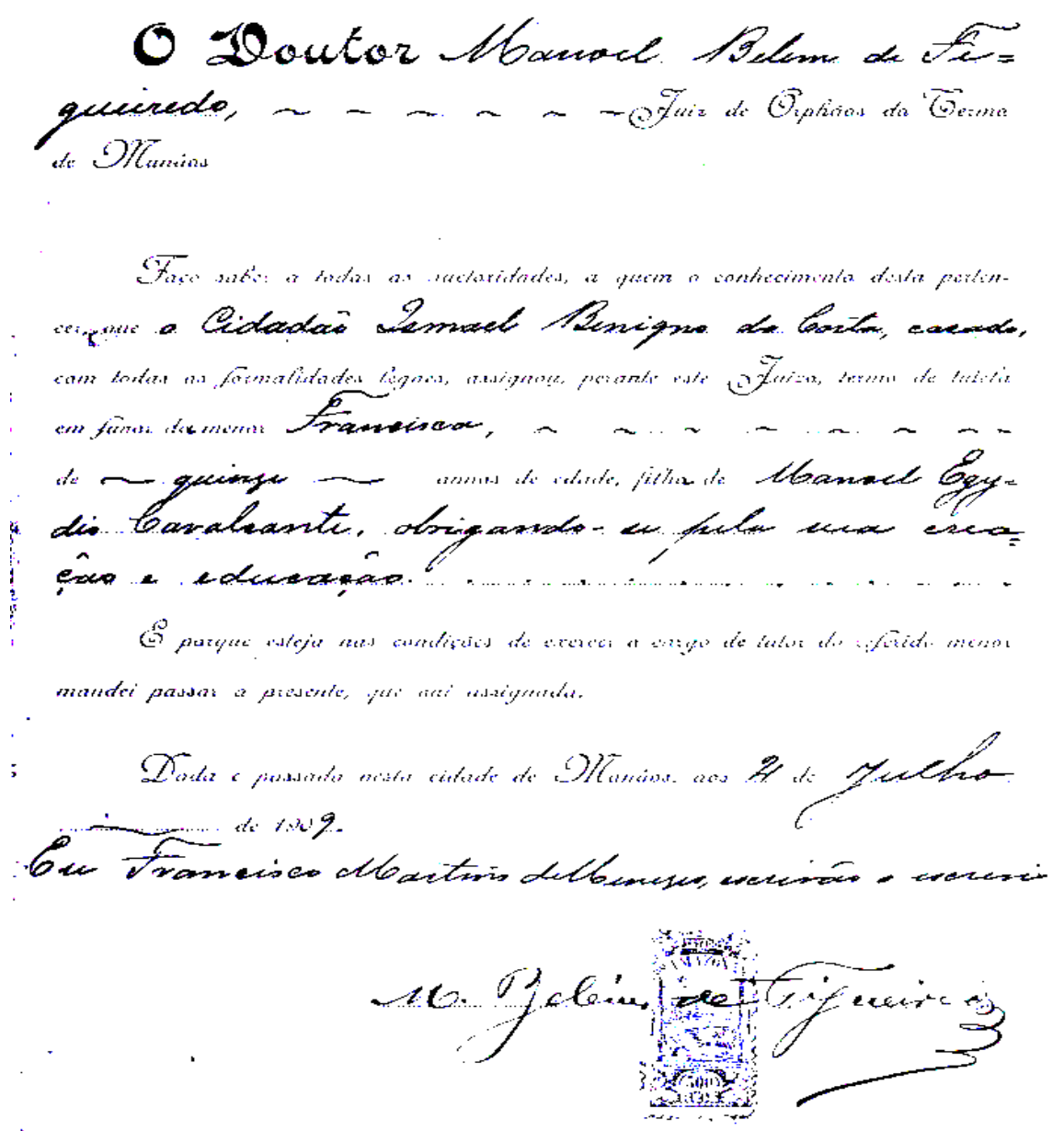

Fonte: Processo de Tutela a favor de Ismael Benigno da Costa. Depósito Público do Tribunal de Justiça do Amazonas.

Caso o tutelado não cumprisse com suas obrigações frente ao seu tutor, castigos físicos eram impressos como base da repressão doméstica: 
Revista Brasileira de História \& Ciências Sociais - RBHCS

Vol. 13 No 25, Edição Especial de 2021

Ao juizo de orphãos da capital, (...) fez apresentar (...) o menor de oito annos, Lindolpho Moreira, fugido da casa do sr. Gregorio Forte, (...) onde diz ter sido seviciado (Ibidem. "Menor Seviciado", 18-9-1917.)

Para livrarem-se de espancamentos, estupros, maus-tratos, exploração a fuga era uma alternativa, mas nem sempre uma possibilidade viável e a longo prazo, uma vez que a polícia estaria no encalço do menor para levá-lo ao seu tutor ou ao juízo de órfãos para ser encaminhado a outro tutor. tutelados ou não, o cotidiano impunha disciplina. Muitas vezes levavam crianças, adolescentes e menores a práticas que demonstravam seus limites em suportar as pressões cotidianas do meio, que poderiam estar além de suas capacidades de aceitação. Nesses casos, o suicídio era uma alternativa de libertação (sobre o suicídio da menor Antoni Maria Carneiro, no dia 19 do corrente mez. Jornal do Comércio, Factos Policiaes: 28 de julho de 1909).

Não era somente pelo trabalho que era vantajoso ao tutor possuir um menor. De acordo com o Código Civil de 1916 (Código Civil da República. Lei n 3071 de $1^{\circ}$ de janeiro de 1916), vantagens eram oferecidas às famílias que se dispusessem à tutoria. Uma espécie de dote, em caso de resgate por mandado judicial, seria pago ao tutor como recompensa aos seus serviços, uma obrigatoriedade da família do menor que independia da vontade, ou seja, caso os progenitores do tutelado se negassem a pagar ou a repartir os bens de direito do menor em benefício do tutor, o juizado competente acionaria os pais do menor tutelado, obrigando-os ao pagamento ou partilha dos bens de herança, além dos tutores por lei terem o direito de receberem "uma gratificação por seu trabalho (e) não tendo os pais do menor fixado essa gratificação, arbitra-la-á o juiz, até dez por cento, no máximo, da renda líquida anual dos bens administrados pelo tutor" (Idem. Art. 431. Parágrafo único ).

Pelas vantagens representadas pela posse dos menores, muitos tutores se negavam em entregá-los a seus pais, mesmo já tendo expirado o período legal da tutela. Isso ocasionava conflitos entre tutores e pais ou outros responsáveis/parentes e que iam parar na polícia, como a nota que afirma que “José Ferreira da Silva queixou-se também contra Antonio França, que se recusa 
Revista Brasileira de História \& Ciências Sociais - RBHCS

Vol. 13 No 25, Edição Especial de 2021

entregar ao queixoso suas quatro filhas menores" (Jornal do Comércio. Factos Policiaes: 19 de maio de 1910).

Ao que tudo indica, fazia parte do senso da sociedade manauara que a fuga de menores tutelados significava uma ilegalidade. Foram significativos os casos de transeuntes que levavam menores que "vagavam" pela cidade às delegacias, e lá descobrindo que eram menores foragidos. Denúncias de moradores que tiveram menores em suas casas em busca de auxílio momentâneo, muitos desses moradores aproveitavam a oportunidade para levarem os menores até a delegacia mais próxima (Jornal do Comércio. Factos Policiaes: 26 de julho de 1909). Pelo rótulo de vadiagem ou por suspeita de serem fugitivos, menores eram alvos de denúncias pelo seu livre trânsito nas ruas da cidade.

Francisco Gonçalves Rosa, residente na parada Filintho, communicou á $1^{0}$ delgacia que uma menor todos os dias vagueia por aquella zona espancando as criações de todos os moradores d'alli. Chamada á fala a dita menor declarou haver fugido da casa onde se acha empregada. A menor acha-se depositada na casa do sr. Capitão João Santos, e, amanhã será enviada ao respectivo juiz dos orphãos, por ordem do dr. Salustino Vieira (Jornal do Comércio. Gazetilha: Menor que promette, 11 de outubro de 1908).

Buscando rastrear os menores que fugiram de seus tutores, percebe-se que a maior incidência de fugas se encontrava entre as idades de 12 a 16 anos, com mais de $90 \%$ dos casos. Em menor incidência, menores entre 7 a 9 anos ou menos, com menos $10 \%$ dos registros policiais.

No que tange aos menores adolescentes na faixa entre 12 a 16 anos, deduziuse que a fuga, se "embrenhando em paragens longínquas", como o dito da época, era a busca de viver de outra maneira para fugir das normas, do impositor quadro de hábitos, horários, funções e medos impostos pela sociedade do período. A adolescência poderia ser vista como uma etapa essencial da vida citadina, período no qual se aguçam olhares e se desperta para novas formas de viver, momento de conquistas e amadurecimento de caráter através de experiências adquiridas no cotidiano da cidade. Era na adolescência, como mostram os números, que brotava a maior incidência de sentimentos de resistência aos ditames sociais entre os que genericamente eram chamados de menores (TORDJMAN, 1979, p.133). 
Revista Brasileira de História \& Ciências Sociais - RBHCS

Vol. 13 No 25, Edição Especial de 2021

Se a fuga significava ilegalidade e a intervenção policial denotava a possibilidade de retorno à prática da tutela, uma estratégia foi muito utilizada por menores do sexo feminino para saírem do poder de mando do tutor dentro do conceito de legalidade e moralidade: o casamento.

Com o casamento, a menor saía da responsabilidade legal do tutor e passava para o encargo do marido. Tal prática talvez significasse maior ou menor grau de exploração, o que consta foi que o método utilizado representou uma válvula de escape para meninas/menores.

Severino Ferreira dos Santos, praça da $3^{\circ}$ companhia do batalhão militar do Estado, foi preso no quartel a que pertence, por ter raptado da casa do snr. Antonio de Souza Sobrinho, á rua Emilio Moreira, a menor Sancha Pinheiro Serrão, de 15 annos de idade, orphã de pae.

A menor foi depositada pelo soldado Severino em casa do major Joaquim Campello de Hollanda Cavalcante, administrador da Casa de Detenção. Estão sendo tratados os papeis para o próximo enlace (Jornal do Comércio. Factos Policiaes: 8 de março de 1910).

As menores e seus pretendentes ou raptores tinham consciência de que, do ponto de vista legal e principalmente moral e ético, os raptos eram punidos com a detenção do raptor ou casamento desse com a menor, sobretudo se fossem comprovadas práticas carnais entre ambos.

O redator foi claro em afirmar que, por mais que o acusado tenha "depositado" a menor na casa do administrador da Casa de Detenção, os "papeis para o próximo enlace” ou os preparativos legais para o casamento já estavam sendo feitos.

A justificação para casamentos abaixo evidencia a emergência de um matrimônio entre uma tutelada e seu pretendente, objetivando evitar o "grande danno" que acarretaria com a demora do enlace. Implícitas ao matrimônio, haveria motivações de honra e moralidade?

Justificação para Casamentos

Dizem Joaquim Vieira da Costa e Francisca de Souza Cavalcante que, tendo contratado casamento um com o outro, desejam que o acto tenha lugar o mais breve possível, por quanto têm de sahir deste Estado na primeira opportunidade e mesmo para evitar o grande danno que a menor demora lhe acarrectaria,; querem por isso prostificar perante V. $\mathrm{Ex}^{\mathrm{a}} \mathrm{o}$ seguinte:

$1^{\mathrm{o}} \quad$ Que o protificante é solteiro, de 26 annos de idade, filho legitimo de João Vieira da Costa e de Maria dos Anjos do Nascimento, artista, natural deste Estado e residente nesta capital. 


\section{Revista Brasileira de História \& Ciências Sociais - RBHCS}

Vol. 13 No 25, Edição Especial de 2021

$2^{\mathrm{O}} \quad$ Que a justificante é solteira de 16 annos de idade filha natural de Felomena Xavier dos Santos, natural do Estado do Ceará e residente neste Estado.

$3^{0}$ Que a justificante é orpha e tem como seu tuctor o senhor Ismael Benigno da Costa.

$4^{\mathrm{O}}$ Que os prontificantes são pessoas bastante conhecidas não são parentes e nem tem impedimentos algum que os imniba de casarem se um com o outro.

Pedem que autuada esta designeis dia hora e lugar para proceder-se a justificação que julgada procedente servirá para supprir a falta dos requesitos legais bem assim seja dispensado os editaes (...)

Conscientimente

Abaixo assignado tuctor da menor Francisca de Souza Cavalcante; de pleno concientimente para a sua referida tutelada, casar-se com o senhor Joaquim Vieira da Costa (Justificação para Casamentos entre Joaquim Vieira Da Costa e Francisca de Souza Cavalcante. Estado do Amazonas. Comarca da Capital. Juízo De Casamentos. 25 De junho De 1910. Depósito Público do Tribunal de Justiça do Estado do AM).

Retorno ao pátrio poder ou através de casamento, eram os únicos meios legais que um (a) tutelado (a) retiraria sobre si o peso da tutela.

Até 1917, a tutoria não estava apresentando resultados satisfatórios quanto ao controle, disciplinamento e repressão dos trânsfugas da menoridade da sociedade manauara. As recorrentes fugas, evidenciadas pelas ocorrências policiais, quase que diariamente mostravam isso. Foi nesse ínterim que administradores públicos de Manaus idealizam a Colônia Correcional para menores delinqüentes, órfãos e os resgatados por ordem judicial.

Para melhor organização da Colonia Correcional, necessario regulamental-a completando-a com a creação duma secção especial para receber menores deliquentes e abadonados, uma especia de Refomatory Schools dos inglezes molhada no systema chamado de Borstal, para educação dos alludidos menores com amor e autoridade, procurando corrigir-se-lhes o carater sem feição penitenciaria, como se pratica na Austria (...) e que substituindo a escola pelo trabalho remunerado (...). (Mensagem lida perante a Assembléia Legislativa na abertura da Segunda Sessão Ordinária da Nona Legislativa pelo Exm. Sr. Pedro de Alcantara Barcelar. Governador do Estado. A 10 de julho de 1917. Manaus - Amazonas. Secção de Obras da Imprensa Publica. Museu Amazônico, p. 161-162).

O projeto da Colônia Correcional seria a materialização de um espaço com objetivos concretos: a submissão de menores, entre outros, em regime de internamento a fim de que tais menores fossem preservados das maledicências da ociosidade, tornando-os úteis aos ideais sociais das elites e autoridades. Assim, sob uma política de adestramento, aos menores internados seriam inculcados os princípios da "educação moral" e "amor ao trabalho" (BARREIRO, 87, p.14). 
Revista Brasileira de História \& Ciências Sociais - RBHCS

Vol. 13 No 25, Edição Especial de 2021

Para as autoridades públicas, os menores seriam educados em favor da obediência, instruídos para a docilidade e passividade no comportamento. O objetivo estava assentado na acolhida de decisões, orientações morais e opiniões sem criticá-las. $O$ intercâmbio de idéias seria feito em uma só direção: dos adultos para os menores, do meio para o sujeito objeto. Como observado na Figura VI, onde há um caixeirinho com trajes e posturas semelhantes aos adultos. Foto de uma das lojas de vestuário de Manaus, 1910.

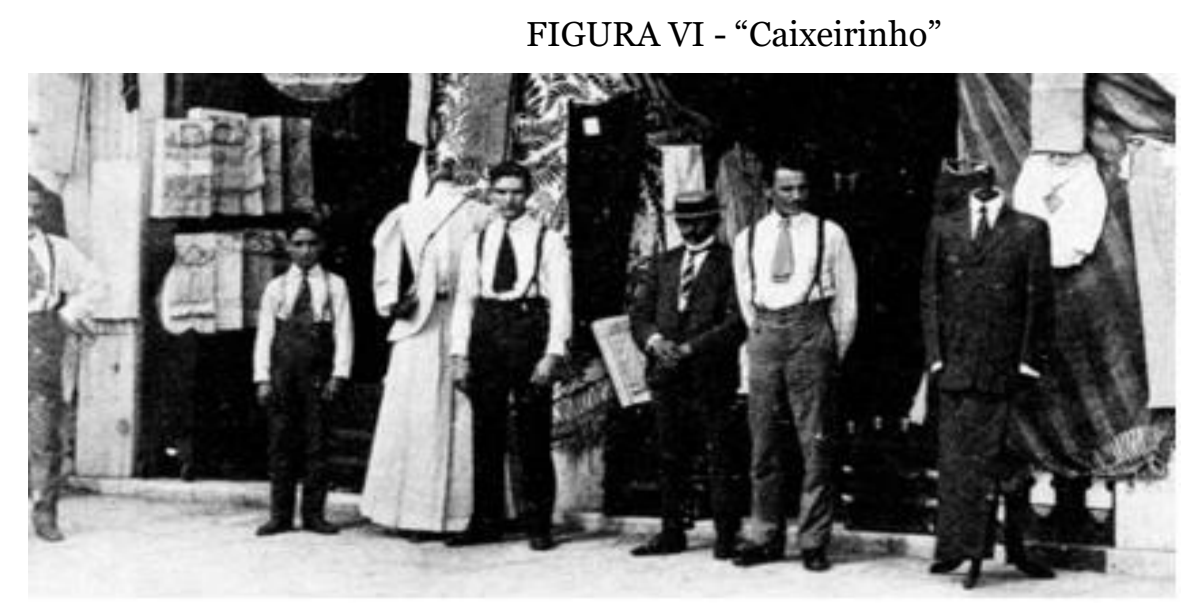

Fonte: Anuário de Manaus, 1910. Museu Amazônico.

Nas ruas de Manaus, a ociosidade era inadmissível. Menores brincando, descansando, conversando ou divertindo-se representava a preguiça e incivilidade, entendidas como inerentes aos populares, ao homem da terra e aos desqualificados. Sendo assim, os administradores públicos impunham normas sociais impeditivas do ócio individual e principalmente do coletivo. Ajuntamentos de menores eram visto com suspeita pelas autoridades por denotar malícia, desocupação e arquitetação perigosa, como registra o Código de Postura do Município:

Art.140 - É prohibido o ajuntamento de menores e de famulos, nas lojas, tavernas, açougues, mercados e ruas, sob pena de multa de $10 \$ 000$, pelo pagamento da qual serão responsáveis os proprietários dos estabelecimentos em que forem elles encontrados, e os paes, tutores ou patrões, quando tal ajuntamento se der nos mercados, ruas e praças (Código de Posturas do Municipio de Manáos, Estado do Amazonas. Lei $\mathrm{n}^{\circ}$ 639, 13 de Setembro de 1910. Secção de Obras da Imprensa Official). 
Revista Brasileira de História \& Ciências Sociais - RBHCS

Vol. 13 No 25, Edição Especial de 2021

Enfim, "a definição legal de parcialidade de direitos e responsabilidades dos menores permitia que se interviesse não apenas sobre aqueles que sofressem alguma acusação específica, mas sobre todos os que fossem identificados como desviantes ou antagônicos a uma determinada representação do modelo ideal da menoridade" (VIANNA, 1999, p. 33).

Referência bibliográfica

Anuário de Manaus. Indicador Ilustrado, 1910. Museu Amazônico. Universidade Federal do Amazonas: Museu Amazônico, 2002, CD-ROM.

BARREIRO, José Carlos. Instituições, Trabalho e Luta de Classes no Brasil do Século XIX. Revista Brasileira de História. São Paulo. V. 7 nº 14 pp. 131/149. Mar./Ago. 87.

BEMVINDO, Vitor. "Escovar a História a Contrapelo": contribuições de walter benjamin para a concepção dialética da história. Revista Trabalho Necessário, V.18, $\mathrm{N}^{\mathrm{O}}$ 35-2020 (jan-abr). Disponível em https://periodicos.uff.br/trabalhonecessario/article/view/40490/23314

BRAGA, Gisella Vieira. Manaós La Belle Époque. Disponível em https://www.youtube.com/watch?v=OkkJA6mxiZU. Vídeo.

BRETAS, Marcos Luiz. A Guerra das Ruas: povo e polícia na cidade do Rio de Janeiro. Rio de Janeiro. Arquivo Nacional, 1997.

CHALHOUB, Sidney. Trabalho, Lar e Botequim: o cotidiano dos trabalhadores no Rio de Janeiro da Belle Époque. São Paulo. Brasiliense, 1986.

COSTA, Francisca Deusa Sena. Quando Viver Ameaça a Ordem Urbana. Dissertação (mestrado em História). São Paulo, Pontifícia Universidade Católica de São Paulo, 1998.

DUARTE, Durango. Indicador Illustrado do Estado do Amazonas de 1910 / Editado por: Courrier e Billiter. Disponível em https://br.pinterest.com. Acesso 28 mar. 2021.

DAOU, Ana Maria Lima. A Cidade, o Teatro e o "Paiz das Seringueiras": práticas e representações da sociedade amazonense na virada do século XIX. Tese de Doutorado apresentada ao programa de Pós-graduação em Antropologia Social do Museu Nacional da Universidade Federal do Rio de Janeiro. Rio de Janeiro, 1998.

Decreto $\mathrm{n}^{0} 847$, de 11 de outubro de 1890. Promulga o Codigo Penal. Disponível em http://www.planalto.gov.br/ccivil_03/decreto/1851- 
Revista Brasileira de História \& Ciências Sociais - RBHCS

Vol. 13 No 25, Edição Especial de 2021

1899/D847.htm\#: :text=DECRETO\%20N\%C2\%BA\%20847\%2C\%20DE\%2011\%2 oDE\%20OUTUBRO\%20DE\%20189o.\&text=Promulga\%200\%2oCodigo\%20Penal. \&text=Art.,que\%20n\%C3\%A30\%20estejam\%2opreviamente\%20estabelecidas.\&te $\mathrm{xt}=3 \% \mathrm{C} 2 \% \mathrm{BA} \% 20 \mathrm{~A} \% 20 l$ i\%2openal\%20n\%C3\%A30,ser\%C3\%A1\%2oregido\%20p ela\%2olei\%2onova.

DIAS, Edinea Mascarenhas. A Ilusão do Fausto. Manaus: 1890-1920. Manaus: Editora Valer.

FAUSTO, Boris. Trabalho Urbano e Conflito Social. 4ª ed. São Paulo: Difel, 1986.

MATOS, Maria Izilda Santos de. Cotidiano e Cultura. Bauru, SP EDUSC 2002.

MATOS, Maria Izilda Santos de. Na trama Urbana. Projeto História, $\mathrm{n}^{\circ}$ 13, junho, 1996, p. 129-150.

MATOS, Maria Izilda Santos de. Trama e Poder. Rio de Janeiro. Sette Letras 1996.

PESAVENTO, Sandra Jatahy. Uma Outra Cidade: o mundo dos excluídos no final do século XIX. São Paulo. Companhia Editora Nacional, 2001.

PESSOA, Alba Barbosa. Infância e Trabalho. Dimensões do trabalho infantil na cidade de Manaus (1890-1920). Dissertação de mestrado. Universidade Federal do Amazonas, 2010.

PESSOA, Marcus. Conheça o lado desumano da Belle Époque que você não aprende nos livros tradicionais. Disponível em

https://marcuspessoa.com.br/conheca-o-lado-desumano-da-belle-epoque-que-vocenao-aprende-nos-livros-tradicionais/?unapproved=4801\&moderationhash=955eo0737bb5118b2803d3cc3895534e\#comment-4801. Acesso em 29 mar. 2021.

PINHEIRO, Maria Luiza Ugarte. A Cidade Sobre os Ombros: trabalho e conflito no porto de Manaus (1899-1925). Manaus, Edua, 1999.

REZENDE, Ivana Otto. O órfão da cidade do látex. XXVII Simpósio Nacional de História. Conhecimento Histórico e Diálogo Social. Natal, julho, 2013. Disponível em

http://www.snh2013.anpuh.org/resources/anais/27/1364933933_ARQUIVO_Oor faodacidadedolateANPUH.pdf

TORDJMAN, Gilbert. A adolescência. Da Fisiologia à Psicologia. São Paulo: Ed. Victor Civita, 1979.

TRINDADE, Etelvian. Cidade Moderna e Espaços Femininos. Projeto História. São Paulo, no 13, junho 96. 
Revista Brasileira de História \& Ciências Sociais - RBHCS

Vol. 13 No 25, Edição Especial de 2021

VIANNA, Adriana de Resende B. O Mal que se Adivinha. Polícia e Menoridade no Rio de Janeiro, 1910-1920. Rio de Janeiro: Arquivo Nacional, 1999.

Recebido em Setembro de 2020

Aprovado em Março de 2021

DOI: https://doi.org/10.14295/rbhes.v13i25.12002 